4. Pavlova T. V., Pavlov A. S. Morphological and physiological indicators of thermal adaptation. Fiziologiya cheloveka 1992; 18(2):108-113 (in Russian).

5. Panin L.E., Kuz'menko D.I. The role of nutrition in the alteration of energy metabolism under stress. Voprosy pitaniya 1982; 3:15-18 (in Russian).

Ekaterina A.Litovchenko Full-time graduate student in the Department of General hygiene

Amur state medical Academy Ministry of health of the Russian Federation 95 Gor'kogo Str., Blagoveshchensk, Amur region, Russian Federation, 675000 Tel. 89638166713, 89246774281 E-mail: ekaterinalitovchenko-89@mail.ru

Natalia V. Korshunova Head of the Department of General Hygiene, doctor of medical Sciences, Professor of the Department of

General hygiene Federal State budgetary educational institution of higher education Amur state medical Academy Ministry of

health of the Russian Federation 95 Gor'kogo Str., Blagoveshchensk, Amur region, Russian Federation, 675000 Tel. 89143893760

UDC 616.248 - 084:618.2 - 06 DOI 10.22448/AMJ.2017.3.137-138

\title{
THE INFLUENCE OF FOLATES METABOLISM GENES ON THE COURSE OF ASTHMA DURING PREGNANCY
}

\author{
Luchnikova T.A., Voitsekhovsky V.V., Prikhodko O.B.
}

Amur State Medical Academy, Blagoveschensk, Russia

Abstracts. The Bronchial asthma (BA) is one of the most urgent problems of pulmonology, at the same time continuous increase in number of patients around the world is noted. Purpose of the research is to determine the influence of genetic polymorphisms of the folates metabolism on asthma course during pregnancy. We are examined 96 pregnant women with BA: from them at 33 patients - controlled BA, at 39 - partially controllable, at 24 - uncontrollable. At 47 patients have a mild current, at 43 - moderate and at 6 - a severe asthma the comparison group consisted of 26 pregnant women without bronchopulmonary pathology.

Key words: bronchial asthma, pregnancy, folates metabolism genes

The Bronchial asthma (BA) is one of the most urgent problems of pulmonology, at the same time continuous increase in number of patients around the world is noted. Study of the question of mutual complication of bronchial asthma (BA) and pregnancy remains relevant due to the increase of the prevalence of asthma in reproductive age women. Parrticular interest is the educational systemic inflammation in asthma, since asthma is an inflammatory process in the bronchial tree. Endothelial dysfunction is a participate in any inflammatory process and can be considered as one of the possible pathogenetic mechanisms of the formation of this disease.

Purpose of the research is to determine the influence of genetic polymorphisms of the folates metabolism on asthma course during pregnancy.

Material and methods. We are examined 96 pregnant women with BA: from them at 33 patients - controlled BA, at 39 - partially controllable, at 24 - uncontrollable. At 47 patients have a mild current, at 43 - moderate and at 6 - a severe asthma the comparison group consisted of 26 pregnant women without bronchopulmonary pathology.

The materials for the molecular and genetic research were DNA samples of 52 pregnant women with asthma and 30 pregnant women without bronchopulmonary diseases (control group).

Results and discussion. During the assessing of frequency of occurrence of MTHFR 677TT genotype depending on the availability of asthma, it was found that in a group of pregnant women with asthma the genotype has been met authentically more frequent than in the control group $(p<0.05)$.

At the same time in case of presence of MTRR66GG gene risk of severe, atopic asthma is increased, the odds ratio (OR) was 9.5 (Cl 1.52, 59.05).

Correlation between allergic form of BA and the presence of the polymorphic genotype of C677T MTHFR ( $r=-0,31$; $p=0.02)$, and mutations in the gene MTRRA66G $(r=-0,30 ; p=0.02)$. The presence of mutations in the gene for MTHFR C677T is more frequently noted in allergic asthma.

In the presence of a polymorphic genotype 677TT asthma exacerbations during pregnancy are more common than in women with normal genotype 677SS ( $p=0.03$ ). The presence of the mutant allele 677T worsens the course of asthma during pregnancy. The relative risk (RR) of asthma worsening in the period of gestation was $5.13(\mathrm{Cl} 0.68,38.62)$. It was found that in pregnant women with of asthma who have MTHFR 677TT and MTRR66GG genes, threatened miscarriage, preeclampsia, chronic fetoplacental insufficiency, chronic fetal hypoxia, fetal intrauterine growth retardation of varying severity are authentically more common. OR of pregnancy complications development if there is polymorphisms of folate metabolism genes MTHFR677TT and MTRR66GG is 6,29 (Cl 3.44, 11.27). The presence of the mutant allele MTRR66GG authentically reduces the indexes of newborn weight and height $(p=0.03)$. In newborns from mothers with asthma and polymorphic genotype MTHFR 677TT, perinatal CNS damage is detected more frequently than that in pregnant women with asthma and normal genotype by this gene. OR 1.66 (Cl 1.09, 2.53). OR of perinatal CNS lesion is $4.04(\mathrm{Cl} 1.33,12.27)$.

Homocysteine $(\mathrm{HZ})$ in a group of pregnant women with asthma was significantly higher than in the comparison group $(p<0.05)$. While the more hard proceeded BA, the higher the $\mathrm{HZ}$ level recorded in pregnant women. When hyperhomocysteinemia often marked by the deterioration of the dynamics of BA course in gestational period $(r=0.63, p<0.01)$ 
Conclusions. Determination of risk factors of endothelial dysfunction, in particular, polymorphism of genes of folate metabolism, gene of endothelial synthase nitric oxide and homocysteine when planning pregnancy or in early gestation allows to assess the course of BA and the presence of possible complications of pregnancy and the health of the newborn

\section{Reference}

1. Babtseva A.F., Prikhodko O.B., Romantsova E.B., Landishev Y.sfunction S., Kostrova I.V.. Dynamics of mild persistent bronchial asthma course in pregnant women. Breath physiology and pathology Journal, 2012. 46. P.39-43.

2. Voronina L.P. Clinical-diagnostic and prognostic value of the study of endothelial dysfunction and myocardial remodeling in bronchial asthma/ abstract of thesis...doctor of medical sciences. Astrahan', 2012. 48 p.

3. Lavrova O.V., Dymarskaya Y.R. Bronchial asthma and pregnancy. Practical pulmonology. 2015. 4. P. 2-9.

4. Luchnikova T.A., Prikhodko O.B. Features of social-economic status in pregnant women with bronchial asthma. Breath physiology and pathology Journal, Blagoveshchensk, 2015. Issue 56. P.78-82.

5. Prikhodko O.B. Clinical and functional features of bronchial and lung systems and neuro-vegetative regulation in patient with asthma in during pregnancy and their effects on offspring. abstract of thesis...doctor of medical sciences. Blagoveshchensk, 2010. 44 p.

6. Prikhodko O.B. Neurovegetative regulation and hemodynamics of pregnant women with bronchial asthma // Allergology and Immunology Journal. 2009. V. 10, № 1. P. 84.

7. Prikhodko O.B., Babtseva A.F., Romantsova E.B. Influence of clinical and functional features of bronchopulmonary system at pregnant women with asthma on the condition of child. International journal on immunorehabilitation. 2010 . N. 12 . № 2. c.114a.

8. Prikhodko O.B., Babtseva A.F., Romantsova E.B. The role of controlled asthma in the development of complications in pregnancy and impact on the health of newborns. International journal on immunorehabilitation. 2009. T.11, №1. C.38-39.

9. $\quad$ Prikhodko O.B., Babtseva A.F., Romantsova E.B., Landyshev Y.S., Luchnikova T.A., Smorodina E.I., Kostrova I.V. The lack of asthma control during pregnancy as a predictor of perinatal complications. Allergology and Immunology Journal. 2013. V. 14. № 3. P.188-189.

10. Romantsova E.B., Babtseva A.F., Prikhodko O.B.. Medical and social status of pregnant women with asthma. International journal on immunorehabilitation. 2009. P.38a.

11. Luchnikova T.A., Prikhodko O.B., Babtseva A.F., Romantsova E.B., Pogrebnaya M.V., Smorodina. Evolution clinical and epidemiological course of bronchial asthma in during pregnancy. The 11th Sino-Russia forum of biomedical and pharmaceutical science: the conference proceedings. Harbin, 2014. P.166-167.

\section{UDC 174 DOI 10.22448/AMJ.2017.3.138-139 \\ ETHICS AND DEONTOLOGY IN THE PHYSICAL CULTURE AND SPORTS AMONG MEDICAL STUDENTS}

\section{F.S. Mironov, V.V. Moseikina}

Amur State Medical University Blagovescshensk, Russia

Keywords: ethical norms, deontology, the relationship between the teacher and the student, the professional activity of the doctor.

Abstract: The article is devoted to the question of the correct ethical education of medical students and to the relevance of their involvement in regular physical activity.

Maintenance of the physical form is the important condition for doctor's effective activity, the guarantee of endurance, the possibility to overcome overloads, stress, moreover, it is the factor of professional longevity.

The certain ethical norms and rules of conduct exist at any specialty. Deontology among medical students in sports includes issues, which are relating the relationship between the athlete and the coach, as well as the relationship of students among themselves and with rivals. All these aspects will play a role in shaping of the type of communication between the doctor and the patient in future.

Different kinds of sports elaborate the habit to play in a team, when everyone learns to win together with other members of team, that is, they work for a common result. Teamwork - the ability to understand team members without words, to support the game initiative, to enjoy the success of everyone, to experience mistakes together, to give each other the belief in victory, is achieved in sports. These skills are necessary for doctor's communicating with colleagues and patients. The involvement of future doctors in sports disciplines, helps form "fighting" qualities: to fight till victory, to respond to defeat adequately. It is actual, that the experience of sport struggle forms respect for the law, what is important for the development of professional ethics. After all, in sports, as in medicine, where everyone is in sight, we have to subdue emothions, and to "play" only according to the rules.

In sport, the struggle goes on until the last moment, in medical practice the struggle for human life goes the same way. Therefore, in sport and medicine, the time and energy of man is valued as nowhere. Moreover, it is an essential aspect for a medical student that in sport decisions are made instantly, it helps to worked out the speed of reaction and endurance. The balance of competition - cooperation is necessary for students of medical schools. This balance is formed by: greeting the opponent before the start of the com- 